International Journal of Engineering \& Technology, $7(3.12)(2018) 1137-1139$
International Journal of Engineering \& Technology
SPC
Website: $w$ ww.sciencepubco.com/index.php/IJET
Research paper

\title{
New Regulatory Tariff Structure for Green Energy and Electric Vehicles in India
}

\author{
Mukesh C. Verma ${ }^{1}$, Rakesh Ranjan ${ }^{2}$, Rakesh Kumar $^{3}$ \\ ${ }^{2}$ Professor, ${ }^{1,2,3}$ Himgiri Zee University \\ *Corresponding Author Email: ${ }^{1}$ mukeshverma20@yahoo.com, \\ ${ }^{2}$ rakesh.ranjan@hzu.edu.in, ${ }^{3}$ ra 77 kesh@gmail.com
}

\begin{abstract}
Electricity tariff is the price of electricity to be paid by the electricity consumers. Determination of electricity tariff is major function of the Regulatory Commissions of the concerned states. Tariff is analysed through a rational process including important role of all stakeholders, including electricity users. The regulator follows a set process mentioned in Act and Regulations, conducts public hearings before the tariff is determined. Special tariff rates need to be measured for Green Energy and Electric Vehicles (EVs) because of their sustainability in nature. State Electricity Regulatory Commissions (SERCs) have a major role to play in promoting Green Energy and EVs for providing optimum tariff structure for EV charging. Despite of new draft model regulations availability, progress is very slow. Regulators need to build a new cadre and capacity for making their regulations and policies to cater future needs. Time to implement new technology is less and utilities are only working on pilot projects. SERCs need to come forward to play leadership role for protecting an environment by promoting sustainability. In my paper, I would like to analyse current scenario and based on the global practice on various tariff structures to optimise electricity use and promote sustainability, will recommend new tariff structure.
\end{abstract}

Keyword: Tariff, Regulators, Green Energy, Electric Vehicles.

\section{Introduction}

Price of electricity which is paid by consumers is determined by each state's Electricity Regulatory Commission (SERC). In tariff determination process, all the stakeholders including customers are in involved. In the tariff setting process, electricity utilities file their petition on Annual Revenue Requirement (ARR) including costs and revenue to the respective SERC. ARR is scrutinized to accept or modify it. SERC share the application to public for comments followed by public hearings. At last, tariff is approved by SERC and applied to the customers by utilities. Objective of Tariff is to protect the interest of consumers and power utilities, promote economy, competition and efficiency, and provide incentives for efficient utilization and conservation of power [1].

\section{Methodology}

Regulators use various methodologies for tariff determination. In primary manner rate of return is compared with utilities' cost of capital. In the other manners inflation in economies and productivity in efficiency is considered while in cost of service method balance future estimated revenue with the cost incurred. Performance based approach is also considered.

\subsection{Time of Day Tariff and Risk}

Power demands fluctuate throughout the year and within a day. In summers demand is high in afternoon and in winters it is high in evening and night.
Peak requirement is fulfilled by arranging power either through costly power purchase or through banking. Figure 1 shows impact of dynamic tariff.

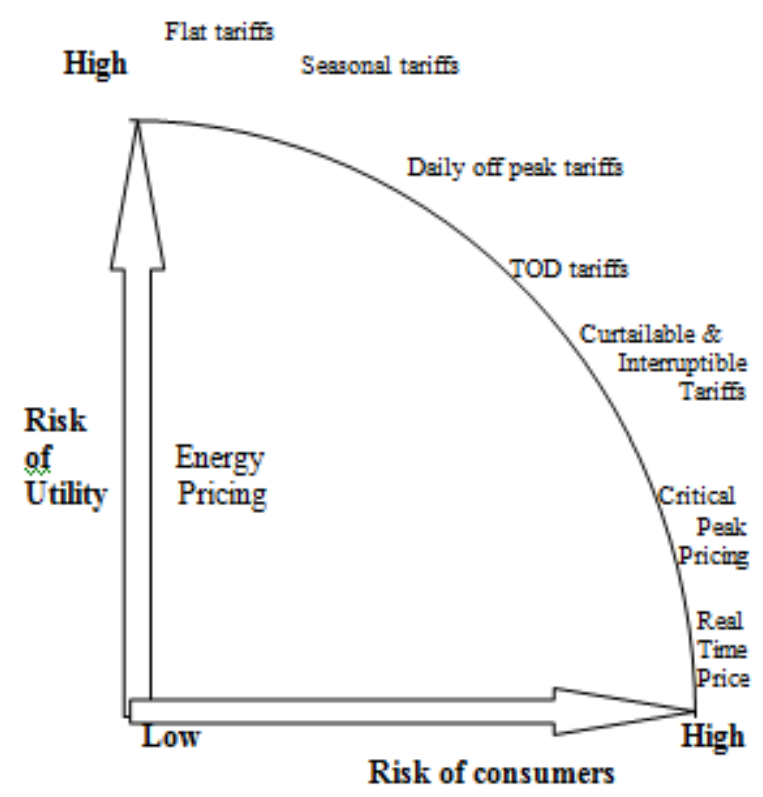

Fig. 1: Impact of dynamic tariff structure 


\subsection{Existing Tariff Structure for Green Energy}

Decreasing peak demand causes less investment and grid stability and also promotes Demand Side Management (DSM) by Time of Day (ToD) tariff and increases role of green energy and enhances sustainability. As it is clear that now role of renewable energies is very important because average cost green energy is reducing and to protect an environment government is promoting use of sustainable energy.

\subsection{Need for New Tariff Structure}

ToD tariff are issued well in advance while due to intervention of new technologies and Smart Grid, Time of use (ToU) tariff is need of an hour. ToU is similar to ToD but works in real time. In ToU, day is divided into time slots but works on real time cost with variable tariff. ToU with the help of Smart grid can reduce peak demand and reduce power shortage.

In future, EVs will be cheaper than fueled vehicles as shown in Figure2 and Figure 3 [8]. Commercial EVs can be cheaper than conventional vehicles by 2020 .

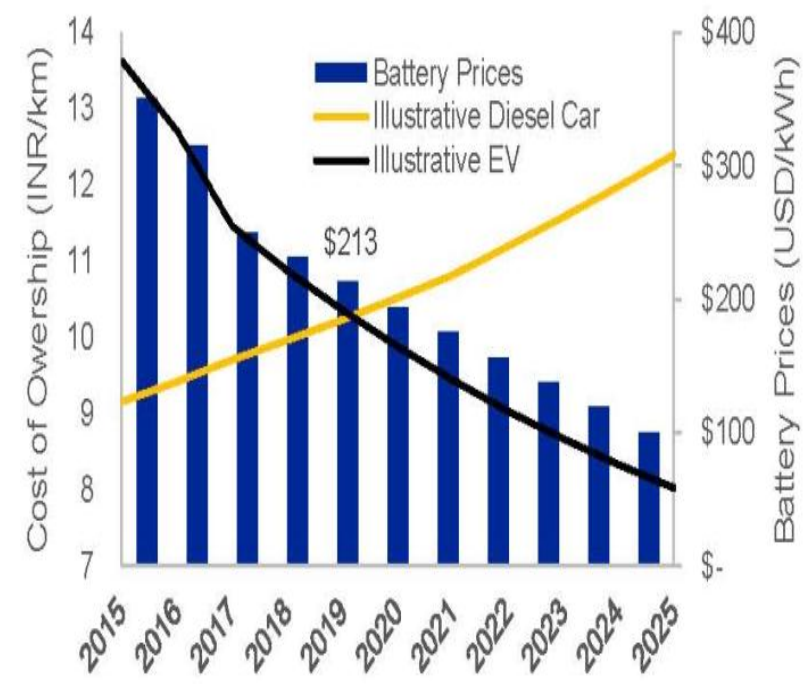

Fig. 2: Commercial EVs Vs Conventional vehicles

And as per figure 3 analysis, Passengers EVs can be cheaper than conventional vehicles by 2023 .

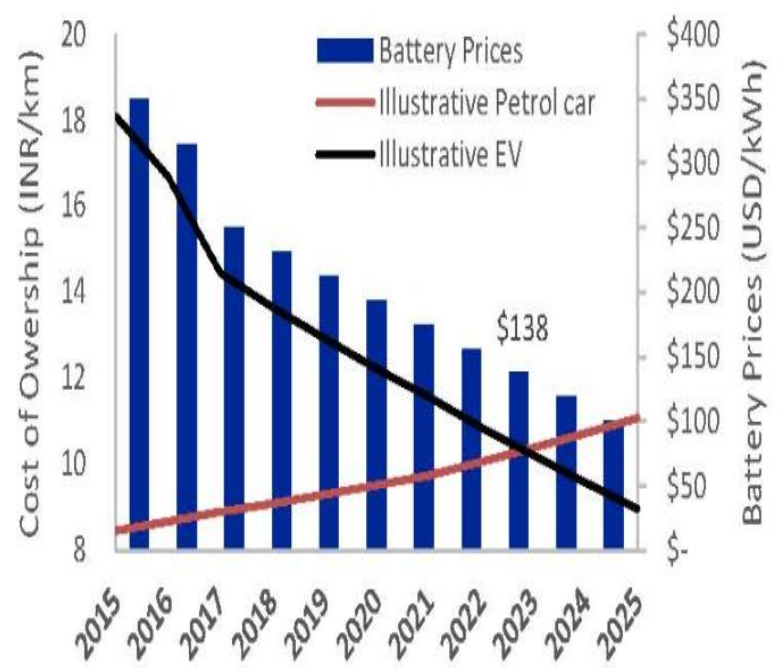

Fig. 3: Passenger EVs Vs Conventional vehicles

\section{Proposed Tariff Structure \& Suggestions for Green Energy and Electric Vehicles (EV)}

Role of Green Energy and Electric vehicles is increasing due to sustainable transport. Role of Regulators and utilities is very crucial in this situation because the government has decided to rollout non electric vehicles by 2030. To encourage number of charging stations and Electric vehicles, regulators need to plan about EVs regulations and incentives. Following points may be considered by SERCs and utilities:

\subsection{Initial Setup of Charging Stations}

Like US and Europe, utilities may install and run charging station by its own to promote sustainability. Regulators to allow pass through of investments made in EV charging infrastructure by the Distribution licensees in tariffs. Simple frame must be provided for franchise agreements between the DISCOMS and private / Public Sector Undertakings/associations for setting up public charging infrastructure.

Regulators must allow distribution licensees to appoint multiple and non-exclusive franchisees within its area of supply for setting up public charging infrastructure.

\subsection{Charging of EV}

To avoid peak demand, charging time of EVs is very crucial. Considering green energy like solar power availability in day time, charging infrastructure may be created at workplace so that charging can be completed by mid day peak of solar output. For remaining users, charging can be promoted in late night hours with concessional rates. ToU can play very important role in this issue.

\subsection{Load Management by Grid Operators}

In this environment charging load is directly controlled by grid operator within the defined parameters set by users.

\subsection{Tempo Electricity Tariff}

In this type of tariff structure, consumers have an option to select rates by option from various available ranges of tariff as per their requirement basis.

\subsection{Strong Awareness Campaign}

Consumer engagement and awareness is a key to success in inducing optimal and judicious use of energy. It should not merely rely on providing enabling technologies but should be undertaking through public engagement and education.

\subsection{Technical Impact of EVs on the Grid}

Due to high loading conditions may occur, the distribution licensees should build resilience by network expansion.

\subsection{New Tariff Category for EV}

A new tariff category for EVs needs to be created SERC by permitting recovery of cost of infrastructure through wheeling charges over and above the average cost of service.

\section{Conclusion}

State Electricity Regulatory Commissions have a major role to play in promoting EVs and providing optimum tariff structure for EV charging without jeopardizing the interest of both utility and 
users. Rate composition can reflect the costs and environmental impacts of the supply and demand of electricity to consumers, giving incentives for individuals to make choices reliable with the collective good because input (electricity) for EVs can replace fossil fuel usages. It is suitable to structure rates so that off-peak charging is promoted. If a utility does not recognize incentive to expand electricity sales to recharge EVs, it can suppress the commercialization of EVs. Utility should also benefit directly from the new EV demand from its grid supporting services.

\section{Future work}

Further research and study is required to understand the potential benefits of dividing domestic electricity use from EV recharging or creating a separate tariff category altogether. This may allow utilities dual benefit of separately structuring domestic electricity tariff to encourage conservation and structuring EV rates to encourage beneficial charging behaviour.

\section{References}

[1] ISGF "Smart Grid Handbook" Delhi, India, November, 2017.

[2] Schabram, S., "Customer Centric Business Models for Smart Grid Development", Masters Thesis, 2013.

[3] Forum of Regulators "Study on Impact of Electric Vehicles on the Grid", September 2017.

[4] Accelerating the Use of Demand Response and Smart Grid Technologies is an Essential Part of the Solution to America's Energy, Economic and Environmental Problems Policy Recommendations for the Obama Administration and 111th Congress, November 24, 2008

[5] Singh A.," Smart Grid Wide Area Monitoring, Protection and Control", International Journal Of Computational Engineering Research (ijceronline.com) Vol. 2 Issue. 7 USA, November 2012.

[6] Prasad I.," Smart Grid Technology: Application and Control", International Journal of Advanced Research in Electrical, Electronics and Instrumentation Engineering, Vol. 3, Issue 5, May 2014.

[7] Jesús Rodríguez-Molina, Margarita Martínez-Núñez., José-Fernán Martínez.and Waldo Pérez-Aguiar, " Business Models in the Smart Grid: Challenges, Opportunities and Proposals for Prosumer Profitability ", Energies 2014, 7, 6142-6171; doi:10.3390/en 7096142 25, September 2014.

[8] Shakti Sustainable Energy Foundation and KPMG, "Dispelling Myths: Electric Vehicles are expensive and will be a burden on the Indian electricity grid", September 2017. 